Relato de experiência

\title{
"Sem mais nem menos on-line": formação continuada de professores de matemática durante a pandemia
}

\author{
"Sem mais nem menos on-line": continuing education of mathematics teachers during the \\ pandemic
}

\author{
"Sem mais nem menos on-line": educación continua de los profesores de matemáticas \\ durante la pandemia
}

\author{
Viviane de Oliveira Santos ${ }^{1}$ \\ [0000-0002-4425-3806] \\ Nickson Deyvis da Silva Correia 2 \\ [0000-0002-9060-9316] \\ Tayná Elias dos Santos 3 \\ [0000-0003-4601-0100] \\ José Monteiro Hilário da Silva ${ }^{4}$ \\ [0000-0001-5421-9647]
}

\section{Resumo}

O objetivo deste artigo é descrever ações desenvolvidas pelo projeto de extensão da Universidade Federal de Alagoas "Sem mais nem menos on-line", mais especificamente sobre a participação de professores de matemática da Educação Básica no projeto. Devido à pandemia da Covid-19, o projeto de extensão "Sem mais nem menos" que atua desde 2016 em escolas públicas de Alagoas reformulou o projeto para também contribuir com a formação continuada de professores, mas de uma forma diferenciada, colaborativa e on-line. A participação dos professores aconteceu em webconferências e um grupo de professores também acompanhou estudantes em atividades realizadas pela equipe do projeto por meio de lives no Instagram. Muitos estudantes e professores passaram a realizar suas atividades de forma remota e o projeto buscou aproximar a teoria, a prática e a realidade do professor, considerando também seus saberes experienciais. Nossas fontes para a escrita foram materiais coletados por e-mail e questionários preenchidos no Google Forms, além das vivências durante o projeto. Os professores, além de compartilharem e repensarem seus saberes, consideraram que houve mudanças na forma de pensar o ensino de matemática depois da participação no projeto, com destaque para um olhar mais atento em trabalhar a matemática de forma mais descontraída e envolvida com o cotidiano. $O$ fato de o projeto ter beneficiado a prática docente nos fez entender que o projeto cumpriu um de seus objetivos que foi de proporcionar um espaço de formação continuada de professores de matemática.

Palavras-chave: Ensino de matemática. Formação de professores. Projeto de extensão. Pandemia.

\footnotetext{
${ }^{1}$ viviane.santos@im.ufal.br, Doutora em Educação Matemática, Docente da Universidade Federal de Alagoas (Ufal), Maceió/AL/Brasil.

${ }^{2}$ nickson.correia@im.ufal.br, Licenciado em Matemática, Mestrando em Ensino de Ciências e Matemática pela Universidade Federal de Alagoas (Ufal), Maceió/AL/Brasil.

3 tayna-elias@hotmail.com, Licencianda em Matemática pela Universidade Federal de Alagoas (Ufal), Maceió/AL/Brasil.

${ }^{4}$ josemonteirosilva321@gmail.com, Licenciando em Matemática pela Universidade Federal de Alagoas (Ufal), Maceió/AL/Brasil.
} 


\begin{abstract}
The objective of this article is to describe actions carried out by the project of extension of the University of Alagoas "Sem mais nem menos on-line", more specifically about the participation of math teachers of Basic Education in the project. Due to pandemic the Covid-19, the extension project "Sem mais nem menos" that has acted since 2016 in public schools in Alagoas reformulated the project to also contribute wiht a continued teacher training, but a differentiated, collaborative and online. The teacher participation it happened in webconferences and a group of professors also accompanied students in activities carried out by the project team through lives on Instagram. Many students and professors passed to performe their activities remotely and the project sought to approximate theory, practice and reality of the teacher, also considering their experiential knowledge. Ours sources for the writing were materials collected by e-mail and questionnaires filled at the Google Forms, além das vivências during or projecto. The teachers, apart from sharing and rethinking their knowledge, considered that there waschanges in the way of think math teaching after the participation of the project, with emphasis to on a closer look at working mathematics in a more relaxed way and involved with everyday life. The fact that the project benefited teaching practice made us understand that the project fulfilled one of its objectives, which was to provide a space for the continuing education of mathematics teachers.
\end{abstract}

Keywords: Math teaching. Teacher training. Extension project. Pandemic.

\title{
Resumen
}

El objetivo de este artículo es describir acciones llevadas a cabo por el proyecto de extensión de la Universidad de Alagoas "Sem mais nem menos on-line", más concretamente sobre la participación de professores de matemáticas de Educación Básica en el proyecto. Debido a la pandemia del Covid19, el proyecto de extensión "Sem mais nem menos" que actúa desde 2016 en las escuelas públicas de Alagoas reformuló el proyecto para contribuir también con una formación continua del profesorado, pero diferenciado, colaborativo y on-line. La participación de profesores ocurrió en las webconferencias y un grupo de profesores también acompañó a los estudiantes en las actividades que realiza el equipo del proyecto a través de vidas en Instagram. Muchos alumnos y profesores pasaron a realizar sus actividades de forma remota y el proyecto buscó aproximar la teoría, la práctica y la realidad del docente, considerando también sus conocimientos experienciales. Nuestras fuentes para la redacción fueron materiales recopilados por correo electrónico y cuestionarios llenados en Google Forms, além das vivências during o projecto. Los profesores, además de compartir y repensar sus conocimientos, consideraron que hubo cambios en la forma de pensar la enseñanza de matemáticas luego de la participación del proyecto, con énfasis en una mirada más cercana para trabajar las matemáticas de una manera más relajada e involucrada con la vida cotidiana. El hecho de que el proyecto haya beneficiado la práctica docente nos hizo comprender que el proyecto lograba uno de sus objetivos que era tener un espacio para la formación continua de profesores de matemáticas.

Palabras claves: Enseñanza de matemáticas. Formación de profesores. Proyecto de extensión. Pandemia.

\section{Introdução}

Devido à pandemia da Covid-19, em 2020, muitos estudantes e professores da Educação Básica passaram a desenvolver suas atividades de forma virtual. Foi assim que a equipe do projeto de extensão "Sem mais nem menos" ${ }^{5}$ lançou o "Sem mais nem menos on-

\footnotetext{
${ }^{5}$ Para maiores informações, ver o site do projeto: https://sem-mais-nem-menos.webnode.com/
} 
line", uma adaptação para este momento, cujas primeiras ações foram realizadas no período de maio a agosto de 2020, nossa primeira etapa do projeto ${ }^{6}$.

Além de contribuir no processo de aprendizagem dos estudantes participantes, essa adaptação do projeto contribuiu na formação continuada de professores. O foco do nosso artigo é descrever essa participação dos professores, visando também avaliar como um projeto colaborativo e on-line pode contribuir na formação continuada de professores de matemática. Nossas fontes para a escrita foram materiais coletados por e-mail e questionários preenchidos no Google Forms, além das vivências durante o projeto.

O projeto de extensão "Sem mais nem menos", do Instituto de Matemática da Universidade Federal de Alagoas (IM-Ufal), realiza um conjunto de ações na pesquisa em ensino de matemática, com o objetivo geral de diminuir lacunas existentes entre a matemática abordada em sala de aula e o cotidiano do estudante. Tais ações possibilitam que estudantes e professores de matemática da Educação Básica da rede pública de ensino, do estado de Alagoas, percebam a existência da matemática no dia a dia, bem como suas relações interdisciplinares. Cada ação do projeto aborda uma temática e, dentre as temáticas abordadas pelo projeto, têm-se "matemática nas profissões", "matemática nas disciplinas escolares", "matemática nas estações do ano" e "matemática na cultura alagoana". Para cada temática, foram elaborados e aplicados materiais didáticos como jogos e atividades que, além de abordarem alguns conteúdos matemáticos vistos em sala de aula presentes no cotidiano dos estudantes e trabalharem a interdisciplinaridade, possibilitam aguçar a curiosidade dos estudantes, motivando-os a estudar. (SANTOS; CORREIA; NASCIMENTO, 2021)

A equipe do projeto participou de eventos locais, regionais e nacionais, voltados às pesquisas em ensino de matemática, nos quais houve compartilhamento de resultados e ideias, discussões acerca dos temas e solicitações dos materiais para professores reaplicarem nossos trabalhos. Dessa forma, a equipe viu no "Sem mais nem menos on-line" uma oportunidade de proporcionar a participação de professores de matemática de escolas públicas ou particulares de qualquer estado do país, bem como a participação dos estudantes.

O objetivo principal do projeto de extensão original sempre foi atrelar conteúdos matemáticos e o cotidiano, na tentativa de diminuir a falta de interesse dos estudantes na disciplina de matemática. Muitos professores, em constante desafio de fazer com que os estudantes se interessem pela disciplina, têm essa mesma preocupação e buscam novas formas de ensinar. Com a pandemia, isso se tornou ainda mais desafiador, professores buscando formas de ter uma melhor participação dos estudantes nas aulas e pensando em como abordar conteúdos de forma interativa mesmo que de forma on-line e sem tantos materiais disponíveis. Foi assim que o projeto, cujo foco principal era na participação dos estudantes, acrescentou momentos dedicados também aos professores, contribuindo assim com uma formação continuada de forma diferenciada, colaborativa e on-line.

A importância da formação continuada de professores é alvo de muitas pesquisas. Nóvoa (1992, p. 4, p. 13) disse que "a formação de professores é o momento-chave da socialização e da configuração profissional" e, além disso, esse mesmo autor ressalta sobre a participação em formação como sendo "um investimento pessoal, um trabalho livre e criativo sobre os percursos e os projectos [sic] próprios, com vista à construção de uma

${ }^{6}$ Vale ressaltar que o projeto continuou com outras etapas. 
identidade, que é também uma identidade profissional.". Apesar de avanços em relação à formação de professores, nota-se a carência em propostas de metodologias de ensino, sobretudo em relacionar a prática docente com a realidade dos estudantes, conforme encontramos em Manrique, Moreira e Maranhão (2016a; b, apud SANDES; MOREIRA, 2018, p. 102):

Entendemos que a formação de professores que ensinam Matemática, embora tenha tido avanços significativos, é bastante carente de investigações, sobretudo na proposição de novas metodologias de ensino. O mesmo pode-se dizer da prática docente voltada para a realidade do estudante, [...] adotando metodologias inovadoras, capazes de estimular quem ensina e quem aprende Matemática.

Segundo Ferreira (2013), geralmente a formação continuada está relacionada com a ideia de frequentar cursos cujos objetivos são atender às carências do professor e ter resultados predeterminados, seja de implementação de currículo ou metodologia de ensino. Sendo assim, inicia-se com uma teoria desenvolvida longe da escola, fazendo com que as propostas sejam feitas de modo fragmentado, compartimentalizado e descontextualizado da realidade do professor, não levando em consideração suas opiniões, experiências e necessidades. Dessa forma, em nosso projeto, trabalhamos com professores e estudantes ao mesmo tempo, aproximando a teoria, a prática e a realidade do professor.

Buscamos valorizar os saberes docentes, como Manrique e André (2013, p. 139) que se preocupam em "investigar as relações vividas em situações de formação, que podem desencadear mudanças de atitudes, concepções e práticas". Eles seguem Charlot (2000, p. 61) ao dizer que "a ideia de saber implica a de sujeito, de atividade do sujeito, de relação desse sujeito com os outros (que co-constroem, controlam, validam, partilham esse saber)", considerando que o saber pode ser de caráter dinâmico e em constante transformação.

Além disso, como ressalta Tardif (2012, pp. 38-39), não se tem como desprezar os saberes experienciais dos professores, pois eles "desenvolvem saberes específicos, baseados em seu trabalho cotidiano e no conhecimento de seu meio. Esses saberes brotam da experiência e são por ela validados.", sendo reconhecidos quando os professores exibem suas ideias, tanto sobre os saberes curriculares e disciplinares quanto sobre sua própria formação.

Nesse espaço que reservamos para trabalhar uma formação continuada de professores, partimos do pressuposto que os professores poderiam colaborar conosco para atingir os objetivos do projeto, ao mesmo tempo que poderiam compartilhar e repensar seus saberes, assim como os membros do projeto. Os professores estavam à vontade para discutir sobre sua própria formação, reconhecendo que eles são também sujeitos do conhecimento. Isso está de acordo com o que relata Tardif $(2012$, p. 240) sobre a formação dos professores:

[...] reconhecer que os professores de profissão são sujeitos do conhecimento é reconhecer, ao mesmo tempo, que deveriam ter o direito de dizer algo a respeito de sua própria formação profissional, pouco importa que ela ocorra na universidade, nos institutos ou em qualquer outro lugar. 
Foi nessa abordagem de um espaço de formação continuada, sendo colaborativa, online e valorizando os saberes docentes, que o projeto de extensão "Sem mais nem menos on-line" aconteceu. Iniciaremos explicando a metodologia do projeto.

\section{0 projeto de extensão "Sem mais nem menos on-line"}

O "Sem mais nem menos on-line" consiste em realizar lives pelo Instagram do projeto para estudantes do Ensino Fundamental II e Ensino Médio, e webconferências para professores de matemática. Os objetivos do projeto são proporcionar aos estudantes momentos descontraídos e interessantes para aprender matemática, e proporcionar aos professores a oportunidade de desenvolver outras habilidades no modo como ensinar matemática, mostrando alternativas atrativas de abordar alguns conteúdos matemáticos. $\mathrm{Na}$ primeira etapa do projeto, cada live abordou uma atividade ou jogo dentre as temáticas já trabalhadas na versão original do projeto e, em cada webconferência, discutiu-se o material didático apresentado nas lives, bem como ele poderia ser aplicado também presencialmente. Tivemos como envolvidos: a equipe do projeto (formada por duas docentes universitárias, oito estudantes de licenciatura em matemática e dois professores da Educação Básica); professores e estudantes da Educação Básica.

Essa equipe múltipla de saberes vem defender a parceria entre a universidade e a escola, concordando assim com Ferreira (2013, p. 150) que diz: "Consideramos que a parceria entre a universidade e a escola é um caminho fecundo e viável para uma mudança significativa no ensino e na aprendizagem da Matemática em todos os níveis". Além disso, como diz Boavida e Ponte (2002), diversificar uma equipe pode acontecer naturalmente devido os objetivos do trabalho e colabora em se ter múltiplos olhares sobre uma mesma realidade, contribuindo com um melhor esboço e mais abrangente dessa realidade.

Após o processo de organização de como o projeto viria a acontecer, foram abertas as inscrições. Os professores de matemática ao se inscreverem, também deveriam ter a concordância da gestão da escola em que trabalhavam. Depois dos primeiros encontros, passamos a ter dois grupos de professores, um denominado como "Acompanhante de alunos e participante das webconferências" e outro como "Participante das webconferências".

Os professores inscritos como "Acompanhante de alunos e participante das webconferências", depois de inscritos, enviaram uma relação com grupo de estudantes independente da série ou turma. Esses professores tinham a responsabilidade de organizar tais estudantes, colocando-os para assistir as lives, discutir com eles os questionamentos e coletar os materiais solicitados, além de apresentar nas webconferências os resultados e possíveis situações que vieram a surgir. Os professores inscritos como "Participante das webconferências" tinham a responsabilidade apenas de assistir as lives e participar das discussões nas webconferências.

Vale destacar que os professores se inscreveram no projeto de forma voluntária e aqueles que permaneceram até o fim se comprometeram a trabalhar para alcançar os objetivos do projeto. Isso vem a caracterizar o projeto também como um relacionamento de colaboração, conforme diz Ferreira (2013, p. 152):

Para Hall e Wallace (1993), os relacionamentos de colaboração implicam que "todos os parceiros valorizem esta forma de trabalhar o suficiente para comprometerem-se a fazê-lo: eles escolhem se engajar em um trabalho conjunto para alcançar metas comuns" (p. 105). A colaboração envolve um 
grau significativo de parceria voluntária, que a distingue de um relacionamento de dominação e submissão.

O projeto de extensão "Sem mais nem menos on-line" apresentou nesta etapa sete lives, abordando temáticas e materiais didáticos elaborados ao longo do projeto original. Cada live abordou um material didático e cada material sofreu adaptações para o momento on-line.

Os materiais didáticos foram apresentados na seguinte ordem: 1) "O compasso do frevo", atividade que evidencia a matemática na sombrinha do frevo usando construção geométrica com régua e compasso, abordando os conteúdos de polígonos, área e retas opostas pelo vértice; 2) "Jogo do pontinho: os hexágonos das abelhas", jogo que destaca a existência da matemática na primavera por meio da organização interna das abelhas na polinização e armazenamento do mel, trabalhando o raciocínio lógico e abordando conceitos de otimização, ladrilhamento, geometria, área e volume; 3) "Arraiá geométrico", atividade que destaca as formas geométricas nos passos da quadrilha junina, abordando os conteúdos polígonos e ângulos; 4) "Operacores: a simetria através das operações", atividade que relaciona matemática e arte, abordando operações aritméticas, simetria e círculo cromático; 5) "Coordenando: resolvendo desafios através de coordenadas", atividade que relaciona matemática e geografia, abordando o sistema cartesiano e o mapa do Brasil; 6) "Quilombo: a matemática da capoeira e do coco de roda", atividade que destaca a matemática presente no quilombo alagoano, usando construção geométrica com régua e compasso e abordando os conteúdos ângulos, distância e ponto médio; e 7) "Guerreiro alagoano: o chapéu triangular", atividade que destaca os números triangulares no chapéu do guerreiro alagoano, abordando os números figurados, multiplicações de números naturais e a soma de Gauss. ${ }^{7}$

As lives eram inicialmente divulgadas no Instagram do projeto e os professores também recebiam os materiais de divulgação por e-mail. Para algumas lives, foram necessários vídeos prévios com a finalidade de pedir que os estudantes fizessem algo que seria necessário para o dia da live. Os materiais de divulgação indicavam, além do dia e horário da live, materiais necessários e alternativos, os quais os estudantes deveriam ter para acompanhar a live, ver Figura 1. Vale destacar que os materiais alternativos oportunizaram ter uma maior quantidade de estudantes participantes e apresentavam aos professores outras possibilidades de realizar atividades usando materiais de fácil acesso aos estudantes.

Figura 1 - Divulgação das lives.

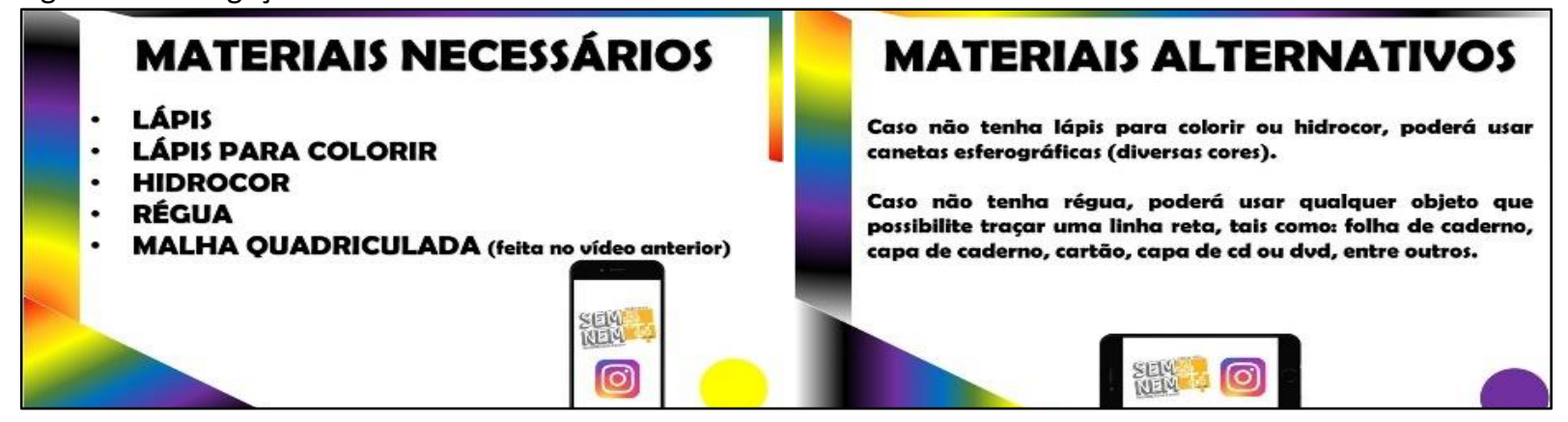

Fonte: Arquivos do projeto de extensão "Sem mais nem menos on-line", 2020.

\footnotetext{
${ }^{7}$ Sobre as lives e resultados da primeira etapa do projeto, ver Santos et al. (2021).
} 
As lives foram apresentadas por membros do projeto no Instagram e os estudantes inscritos pelo professor assistiam e seguiam as instruções descritas nas lives. Os estudantes passavam os materiais (imagens e respostas de questionamentos) para seus professores que, no momento oportuno, enviavam esses materiais por e-mail junto com um documento de pré-análise de respostas e depois apresentavam nas webconferências.

As webconferências foram encontros on-line previamente marcados e realizados usando a plataforma Google Meet, voltadas a todos os professores participantes do projeto. Os objetivos eram: ouvir o feedback dos docentes em relação às lives, o processo de acompanhamento dos estudantes durante cada atividade, os pontos positivos e negativos; discutir as estratégias utilizadas para os estudantes participarem e realizarem as atividades; aproximar os professores da equipe do projeto; e compartilhar experiências docentes.

A primeira webconferência foi responsável por apresentar a metodologia do projeto. A segunda webconferência aconteceu após a primeira live, com o intuito de responder possíveis dúvidas que viessem a surgir, bem como certificar que o processo estava tendo êxito. Em seguida, as webconferências aconteceram a cada duas lives realizadas.

\section{Participação dos professores}

Ao todo foram quarenta professores participantes do projeto, sendo doze como "Acompanhante de alunos e participante das webconferências", e vinte e oito como "Participante das webconferências", isso considerando os professores que participaram pelo menos de uma webconferência.

Após concluir as atividades do projeto, elaboramos dois questionários para os professores, visando conhecer melhor esses participantes, saber da motivação deles em participar do projeto e verificar se os objetivos do projeto foram alcançados. O primeiro, denominado "questionário geral", foi enviado a todos os professores participantes e recebemos respostas de quinze professores. O segundo, denominado "questionário específico", foi enviado aos professores que estavam acompanhando estudantes e recebemos respostas de dez professores. Ressaltamos que esses dez professores do segundo questionário estão contidos nos quinze professores do questionário geral. Apresentaremos a seguir alguns dados coletados dos questionários.

\subsection{Conhecendo os professores}

Os professores que responderam o "questionário geral" são dos estados de Alagoas, Ceará, Maranhão, Minas Gerais, Paraíba, Pernambuco e Rio de Janeiro, distribuídos em treze escolas públicas (municipal, estadual e federal) e duas escolas particulares.

Dos quinze professores, nove $(60,00 \%)$ possuem especialização, três $(20,00 \%)$ possuem mestrado, dois (13,33\%) possuem doutorado e um $(6,67 \%)$ possui apenas graduação. Os cursos mencionados foram: Graduação (licenciatura em matemática); Especialização (matemática, ensino de matemática, métodos e tecnologias, pós-graduação em gestão educacional, pós-graduação em licenciatura em matemática, metodologia do ensino de matemática, educação matemática: estratégias); Mestrado (matemática PPGMAT e Profmat); Doutorado (educação); e alguns não especificaram.

Destes professores, dez trabalham em instituição estadual, sete trabalham em instituição municipal, dois trabalham em instituição particular e um trabalha em instituição federal. Vale ressaltar que há casos de o professor trabalhar em mais de um tipo de 
instituição. De acordo com o Gráfico 1, podemos ver que as séries em que os professores lecionam estão bem distribuídas, sendo a maior parte no 70 ano do Ensino Fundamental.

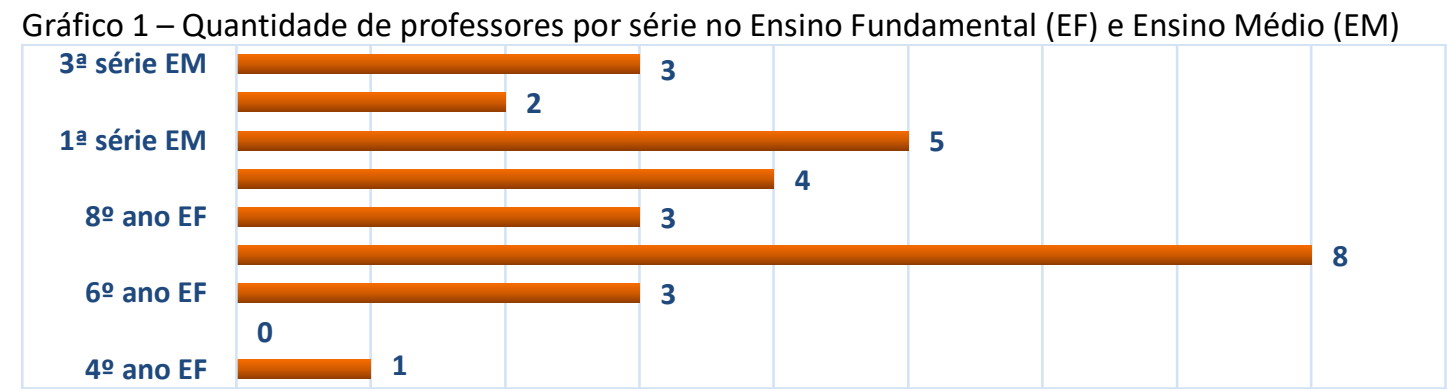

Fonte: Arquivos do projeto de extensão "Sem mais nem menos on-line", 2020.

Alguns professores lecionam em mais de uma série e as séries apresentadas no Gráfico 1 não são as inscritas no projeto, mas sim todas as séries que os professores indicaram lecionar. Além disso, dos quinze professores, oito $(53,33 \%)$ possuem mais de 10 anos em sala de aula, quatro (26,67\%) possuem menos de 5 anos em sala de aula e três $(20,00 \%)$ possuem entre 5 e 10 anos em sala de aula.

Agora vamos a alguns questionamentos sobre a formação continuada e a motivação desses professores em participar do projeto.

Um dos questionamentos foi: "Você costuma participar de formação continuada? Com que frequência?". A maioria dos professores, oito (53,33\%), respondeu "Sim, três vezes ou mais ao ano". Podemos ver as outras respostas no Gráfico 2.

Gráfico 2 - Você costuma participar de formação continuada? Com que frequência?

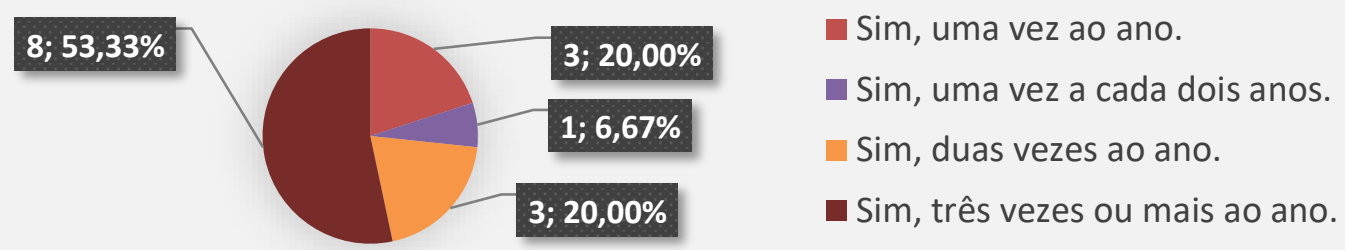

Fonte: Arquivos do projeto de extensão "Sem mais nem menos on-line", 2020.

Sobre o formato dessas formações continuadas que já participaram, nove professores $(60,00 \%)$ responderam "Presencial e Remoto (on-line)", quatro professores $(26,67 \%)$ responderam "Remoto (on-line)" e dois professores (13,33\%) responderam "Presencial".

Devido a nossa proposta de formação continuada ser on-line, pedimos também para os professores que já tinham participado nos dois formatos de formação continuada apontarem diferenças entre os formatos remoto (on-line) e presencial. Vejamos no Quadro 1 as principais diferenças relatadas pelos professores:

Quadro 1: Presencial x Remoto (on-line)

\begin{tabular}{|l|l|}
\hline \multicolumn{1}{|c|}{ Presencial } & \multicolumn{1}{c|}{ Remoto (on-line) } \\
\hline $\begin{array}{l}\text { Positivos } \\
\text { - Maior potencialidade de pôr em prática } \\
\text { algumas situações. }\end{array}$ & $\begin{array}{l}\text { Positivos } \\
\text { - Você aprende, tem retorno dos professores e } \\
\text { - Atividades feitas em grupos. }\end{array}$ \\
\hline
\end{tabular}


- Maior interação entre os professores. Negativos

- Aulas cansativas, repetitivas e não intuitivas.

- Material básico e materiais escritos sem boa qualidade.

- Incômodo do deslocamento.

- Baixa adesão dos professores por conta de horário.

- Os programas ficam um pouco solto, fugindo-se muitas vezes do que foi programado.
- Maior interação com o expositor.

- Com dedicação, tem a oportunidade de se aprofundar bem mais.

- Mais flexível em termo de horário e possibilidade de participação de formações fora do estado.

- As formações ocorrem com mais objetividade e mais precisão.

\section{Negativo}

- Muitas vezes não há uma concentração para o objetivo da formação (porque estamos reunindo trabalho dentro de casa).

Fonte: Arquivos do projeto de extensão "Sem mais nem menos on-line", 2020.

Informamos que dos quinze professores, onze (73,33\%) tiveram sua penúltima formação continuada em 2020. Além disso, nove professores $(60,00 \%)$ disseram ser motivados por parte da gestão escolar em participar de formações continuadas e seis professores $(40,00 \%)$ disseram não ser motivados pela gestão escolar.

Também questionamos sobre o motivo pelo qual os professores participam de formações continuadas. As respostas foram no sentido para estar melhor preparado para conduzir as atividades escolares, aprender novas metodologias de ensino e aprendizagem, discutir sobre o ensino de matemática, aprender novas temáticas, buscar novas ideias, não cair no comodismo e nem parar de aprender, interagir com outras pessoas, aprimorar práticas pedagógicas e melhorar a didática.

Para finalizar essa primeira descrição das respostas dos professores, vejamos alguns comentários sobre a motivação deles em participar do projeto.

Professor: Aprender estratégias e metodologias para o ensino da matemática de forma a promover o interesse e facilitar aprendizagem do conteúdo para meus alunos.

Professor: A procura de algo inovador, pois estou sempre procurando novas formas de trabalhar a matemática com os estudantes, pois os tempos mudaram e nós professores precisamos nos adaptar constantemente. No meu caso sou professor a bastante tempo (30 anos) e sinto a necessidade de acompanhar inovações para não estacionar no tempo $e$ espaço.

Professor: Pretendo fazer um mestrado na área de educação, com foco na educação matemática e suas potencialidades. Achei que o projeto seria uma ótima oportunidade de pôr em prática algumas tendências no ensino da matemática.

Professor: A princípio a gestão me enviou o link da inscrição do projeto, a medida que li gostei bastante da proposta, pois se as formações seguisse um pouco da proposta de vocês ajudaria e muito nós professores.

Professor: Já conhecia o projeto durante a graduação, não tive a oportunidade de participar como estudante (por conta do tempo) e fiquei empolgado quando soube da oportunidade de participar como professor.

Professor: O formato. Pois era tanto para o professor quanto para os alunos.

Professor: Acompanhava o projeto pelas redes sociais e como sou do interior do estado, vi na modalidade remota a oportunidade de participação.

(Depoimentos de professores participantes do projeto, 2020).

Agora que conhecemos nossos professores participantes, suas experiências e suas motivações em relação a participar de uma formação continuada, vamos relatar como os 
dois grupos de professores participaram do projeto.

\subsection{Nas lives}

Ambos os grupos de professores assistiram as lives. Os professores do grupo "Participante das webconferências" eram comunicados que deveriam assistir as lives, para que pudessem participar nas webconferências relatando suas impressões das atividades, sugerindo, comentando, aprendendo com ideias propostas e compartilhando experiências, sendo beneficiados em sua formação continuada e beneficiando outros professores participantes.

Os professores do grupo "Acompanhante de alunos e participante das webconferências", além de serem comunicados sobre as lives, recebiam um documento para uma pré-análise dos materiais enviados pelos estudantes, como alguma construção e respostas de questionamentos. Também eram solicitados comentários dos estudantes e professores, destacando também se os professores trabalharam outros conteúdos ou se fizeram atividades extras usando a live.

Como nosso foco aqui é a participação dos professores no projeto, não iremos descrever as lives. Mas ressaltamos que todos os vídeos estão disponíveis no Instagram e YouTube do projeto, e as descrições e resultados das lives estão em Santos et al. (2021).

A seguir, apresentamos na Figura 2 um exemplo desse tipo de documento referente a uma das lives e, adiante, elencamos alguns comentários dos professores feitos nos documentos de pré-análise das atividades. O objetivo ao pedir esses comentários era verificar se nossa proposta estava tendo êxito, se os professores estavam de fato acompanhando esses estudantes, se eles estavam aproveitando para abordar outros conteúdos, e o que estava sendo observado por eles ao acompanhar as atividades e estudantes.

Figura 2 - Modelo de documento de pré-análise entregue aos professores.
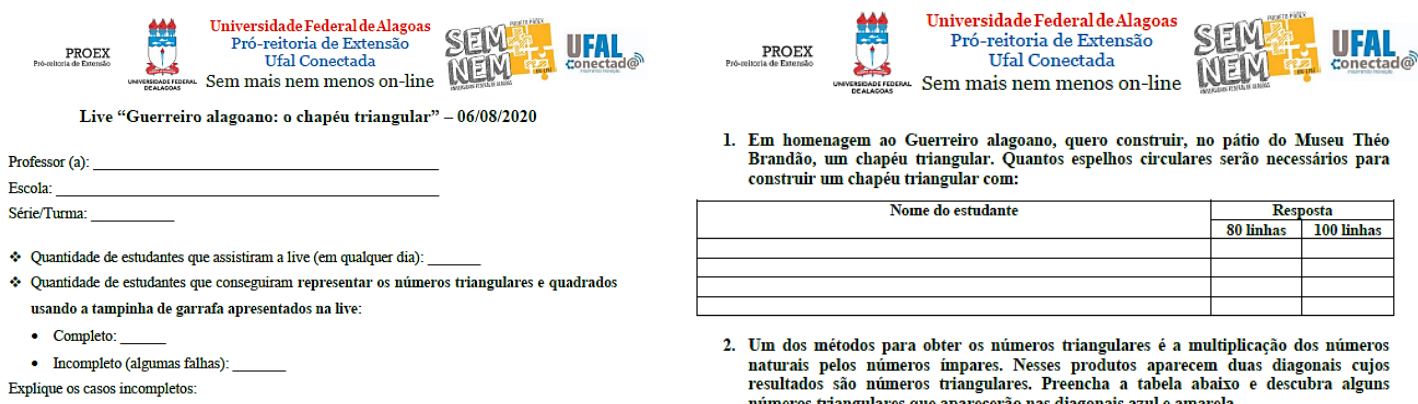

2. Um dos métodos para obter os números triangulares é a multiplicação dos números naturais pelos numeros impares. Nesses produtos aparecem duas diagonais cujos
resultados são números triangulares. Preencha a tabela abaizo e descubra alguns números triangulares que aparecerẫo nas diagonais azul e amarela.

Explique os casos incompletos:
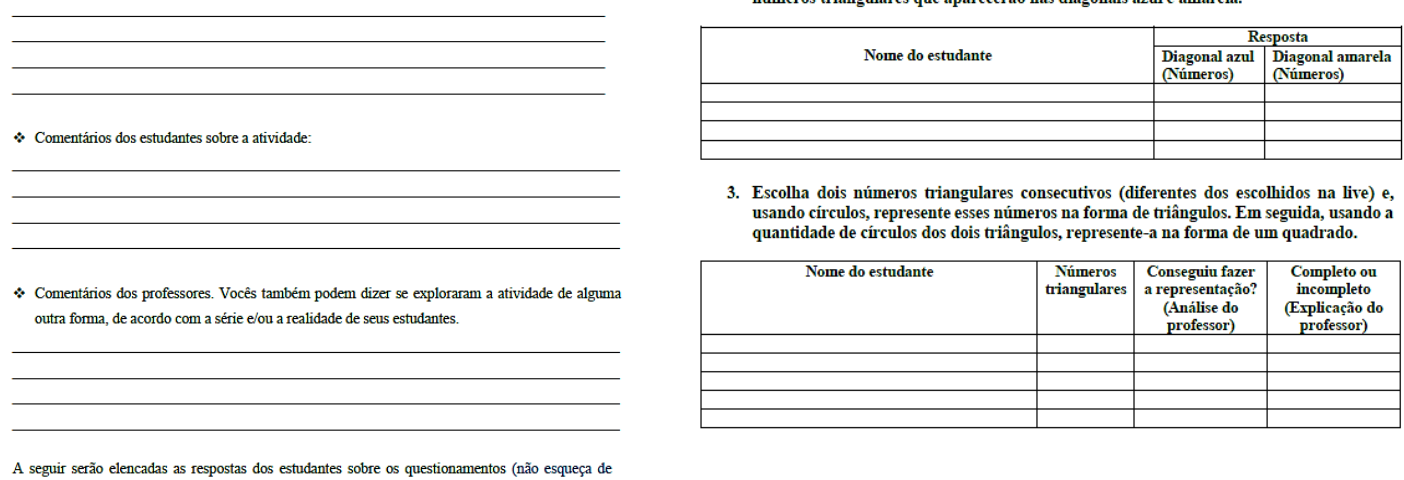

3. Escolha dois numeros triangulares consecutivos (diferentes dos escollidos na live) e, usando circulos, represente esses números na forma de trângulos. Em seguida, usando
quantidade de circulos dos dois triângulos, represente-a na forma de um quadrado.

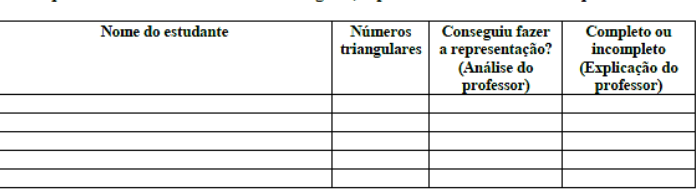

A seguir serão elencadas as respostas dos estudantes sobre os questionamentos (não esqueca de

Fonte: Arquivos do projeto de extensão "Sem mais nem menos on-line", 2020. 
Na live "O compasso do frevo", doze professores acompanharam os estudantes e enviaram os materiais solicitados. Os professores mencionaram sobre a possibilidade de relembrar, conversar e discutir sobre tópicos de geometria, bem como sobre o uso de materiais alternativos. Vejamos alguns comentários:

Professor: A atividade foi bacana pois permitiu relembrar alguns conceitos de geometria.

Professor: Alguns questionaram o porquê de tantos passos para se chegar a figura final, gerando assim uma conversa e explicação sobre tópicos de geometria.

Professor: A atividade foi muito legal, principalmente a live, com estudantes e professores de várias escolas. gostei porque mostrou uma atividade de matemática em geometria que temos dificuldade. gostei de ter alternativas de utilizar os materiais.

(Depoimentos de professores participantes do projeto, 2020).

$\mathrm{Na}$ live "Jogo do pontinho: os hexágonos das abelhas", nove professores acompanharam os estudantes e enviaram os materiais solicitados. Os professores destacaram sobre como a atividade despertou no estudante a curiosidade de encontrar a matemática nas estações do ano, especificamente na primavera, e mencionaram abordar outros conteúdos matemáticos a partir da live, conteúdos extras e conteúdos que precisaram ser revisados. Vale ressaltar também sobre o fato de se remeterem ao uso da atividade de forma presencial, o que reflete a importância na participação do projeto não somente no momento on-line, mas visando aplicar as atividades também de forma presencial. Vejamos alguns comentários:

Professor: Os que assistiram a live fizeram a atividade sem muitas dificuldades. Gostei bastante dessa atividade, acredito que se fosse feito pessoalmente teria um resultado significativo na participação dos alunos.

Professor: A live foi dinâmica devido proporcionar as estações do ano explorando alguns pontos relevantes das estações enfatizando a primavera onde existe o trabalho das abelhas para produção do mel. Diante da problematização que fiz com os alunos a partir da live foi trazer mais elementos acerca do octógono [hexágono], como: os valores dos ângulos, a soma dos ângulos internos, a decomposição do hexágono e as figuras geradas.

Professor: Percebi maior dificuldade na realização da tarefa dessa live em comparação com a primeira. Acredito que o motivo se deu pela falta de empenho dos alunos em realizar duas etapas para mesma tarefa. Muitos também não parecem ter nenhum conhecimento prévio do conceito de formas geométricas o que dificulta muito a realização de tarefas nesse perfil. Por esses motivos enviei uma tarefa/resumo extra, expondo as formas geométricas, como calcular área e perímetro, alguns conceitos sobre posição de retas, etc.

(Depoimentos de professores participantes do projeto, 2020).

Na live "Arraiá geométrico", nove professores acompanharam os estudantes e enviaram os materiais solicitados. Os professores comentaram sobre a dificuldade dos estudantes em relação ao acesso à internet e entendimento do conteúdo de geometria, mas que aproveitaram para trabalhar outros conteúdos, inclusive com atividades complementares. Destacaram também a surpresa em relacionar a matemática com a dança da quadrilha junina e a forma dinâmica e criativa exposta na live. Vejamos alguns comentários:

Professor: Com a pandemia, os alunos estão com problemas de conexão com a internet e muitos desestimulados pela ausência de um calendário escolar e a grande quantidade de atividades enviadas remotamente, mas mesmo assim, aproveitei a atividade para conversar 
com eles sobre os ângulos internos de polígonos, que foi a questão que os alunos mais obtiveram dificuldade para realizar.

Professor: Nunca tinha reparado, nem mesmo imaginado, ser possível retirar matemática da dança da quadrilha. E elaborei uma atividade complementar a partir da live para os alunos, sobre a classificação dos triângulos e dos quadriláteros e também sobre a soma de seus ângulos internos.

Professor: Essa atividade traz de forma lúdica, e divertida, conteúdos que muitas vezes são vistos como abstratos, além disso conduz os estudantes a um novo olhar para a matemática. Um grande desafio foi mostrar pra os alunos quais seriam os vértices da figura, logo muitos não desenharam a figura proposta, e consequentemente as outras respostas baseadas nos desenhos que fizeram foram diferentes das esperadas.

(Depoimentos de professores participantes do projeto, 2020).

$\mathrm{Na}$ live "Operacores: a simetria através das operações", oito professores acompanharam os estudantes e enviaram os materiais solicitados. A ideia de utilizar a folha de caderno para fazer uma malha quadriculada agradou os professores que levantaram a questão de economizar custos de impressão e papel. Relataram também sobre a aplicação do conteúdo da live em aulas, contextualizando a simetria no cotidiano dos estudantes com objetos simétricos ou assimétricos de suas casas. Vejamos alguns comentários:

Professor: Adorei a atividade, já havia realizado atividades semelhantes a essa, através do estudo do plano cartesiano [...] Porém foi muito enriquecedora a ideia de confeccionar a malha com os alunos, sendo essa uma alternativa, tendo em vista que nem sempre há o recurso de xerox disponível na escola para fazer cópias para todos.

Professor: Com relação ao vídeo prévio eu explorei as malhas quadriculadas com figuras semelhantes, cálculo de área e com relação a live tive como estratégia uma ideia de trabalhar a simetria dentro da casa deles, onde eles, pegariam objetos que tivessem algo simétrico. $E$ com isso identificasse os elementos da simetria.

(Depoimentos de professores participantes do projeto, 2020).

$\mathrm{Na}$ live "Coordenando: resolvendo desafios através de coordenadas", sete professores acompanharam os estudantes e enviaram os materiais solicitados. Como a atividade envolvia o plano cartesiano, alguns professores relataram que os estudantes tiveram dificuldades, mesmo sendo feita uma explicação no início da live. De toda forma, os professores destacaram sobre aprender novas metodologias de ensino, o uso da interdisciplinaridade e a importância da confecção de materiais pelos próprios estudantes ao invés de levá-los prontos para sala de aula. Vejamos alguns comentários:

Professor: Atividade bastante interessante, 0 7 ano ainda não tem uma familiaridade com plano cartesiano. Como foi dois vídeos não pude explorar mais e dá uma explicação sobre o assunto, para não atrapalhar as atividades das outras disciplinas. Não tive muitas participações, um aluno falou que não sabia, outro que não iria fazer. Mesmo insistindo $e$ dando suporte para tirar as dúvidas. Gosto bastante desse assunto, já fiz algo parecido com o 3o ano do ensino médio e foi bem proveitoso. Agradeço a oportunidade, pois estou vendo metodologias excelentes, parabéns pelo projeto.

Professor: É muito interessante, ensina não só matemática como também geografia, ensina onde fica localizada as regiões.

Professor: Costumo trabalhar o plano cartesiano junto ao uso de mapas e, também, com jogos, mas achei interessante propor desafios junto com essas atividades. Infelizmente os alunos da escola que atuo estão bem desestimulados e não tem respondido bem as 
atividades (a nenhuma atividade proposta, na verdade). Eu sempre realizo as atividades das lives para tentar ajudar e estimular os alunos e confesso que minha coordenação motora para fazer a malha quadriculada não ajudou muito, rs. Estou achando superinteressante a proposta de construir tudo junto aos alunos, pois tenho o (péssimo) hábito de levar a malha quadriculada pronta, então está sendo ótimo para repensar minhas práticas pedagógicas.

(Depoimentos de professores participantes do projeto, 2020).

Na live "Quilombo: a matemática da capoeira e do coco de roda", sete professores acompanharam os estudantes e enviaram os materiais solicitados. Os professores elogiaram a atividade e disseram ser bem elaborada, diferenciada e interessante. Os destaques são em relação à possibilidade de abordar os conteúdos relacionados à circunferência, aprender sobre a cultura alagoana e o uso do material alternativo. Vejamos alguns comentários:

Professor: A atividade, como as anteriores, são bem elaboradas e diferenciadas. Utilizei essa atividade para explorar os conceitos relacionados ao estudo da circunferência. Elaborei um roteiro de estudo que possibilitasse a compreensão do conteúdo ao passo da construção do pandeiro. A cada etapa da construção foi possível conceituar e diferenciar circunferência de círculo, corda, raio e diâmetro.

Professor: Atividade bastante interessante, para introduzir o conceito de circunferência e seus elementos, além de aprender sobre a cultura. Não abordei a atividade de outra forma, apenas baixei o vídeo e disponibilizei no grupo, para os que não tem conta no instagram. Na outra semana, explorei esse conteúdo com algumas questões sobre as definições e alguns probleminhas.

Professor: Foi uma das minhas lives favoritas. Mais uma vez fiquei surpresa com o material alternativo, muito boa a ideia/dica de usar a própria folha como um compasso.

(Depoimentos de professores participantes do projeto, 2020).

Na live "Guerreiro alagoano: o chapéu triangular", sete professores acompanharam os estudantes e enviaram os materiais solicitados. Os professores mencionaram que o contato com essas atividades os possibilita a buscar novas alternativas de atividades nas aulas de matemática. Mencionaram também a criatividade dos integrantes do projeto e alegaram ser interessante a relação com os números triangulares. Além disso, os professores disseram que a atividade foi proveitosa e significativa no processo de aprendizagem, apesar de algumas dificuldades por parte dos estudantes.

Professor: Nesta atividade, não explorei outras possibilidades de contextualização ou conteúdo. Como sempre as atividades são bem elaboradas e atuais, o que nos possibilita buscar a partir daqui outras possibilidades de atividades para as aulas de Matemática.

Professor: Achei muito legal a live, não conhecia o Guerreiro Alagoano e foi muito interessante ver a relação feita com a matemática. Adorei o desdobramento da atividade somando números triangulares e resultando em quadrados perfeitos, a visualização tornou bem fácil o entendimento. Sempre me surpreendo com a criatividade dos integrantes do projeto, parabéns.

Professor: Nessa atividade, elaborei um vídeo sobre a sequência dos números triangulares, para se familiarizassem melhor com o conteúdo, e outro vídeo de como fazer a atividade. Tiveram bastante dificuldades para entender o que era para ser feito em cada questão. De todas as atividades essa foi a mais trabalhosa com os alunos, tanto que alguns que fazem a atividade não quis fazer por achar muito difícil. É compreensível, pois não estão acostumados com esse tipo de assunto. Apesar disso foi bem proveitosa essa atividade.

(Depoimentos de professores participantes do projeto, 2020). 
Pelos comentários dos professores, já observamos que o objetivo do projeto em relação a fornecer também uma formação continuada parece ter sido alcançado. Os professores foram instigados e impulsionados a pensar em outras possibilidades de aplicação de determinados conteúdos matemáticos, seja de forma on-line ou presencial. Algumas outras observações ainda sobre as lives serão vistas mais adiante quando apresentarmos sobre os questionários finais aplicados aos professores participantes do projeto.

\subsection{Nas webconferências}

Todos os professores participaram das webconferências, tendo cada uma duração média de 2 horas. Nesse espaço, valorizamos o que se pode considerar como algo muito importante em um grupo colaborativo, que é ter o grupo também como fonte de aprendizagem. Isso vai de acordo com o que diz Ferreira (2013, p. 152):

Um ponto relevante na constituição de grupos colaborativos é, a nosso ver, a percepção no grupo como fonte de aprendizagem. Ou seja, o grupo tornase o contexto no qual são criadas oportunidades para o professor explorar e questionar seus próprios saberes e práticas, bem como para conhecer saberes e práticas de outros professores, permitindo-lhe aprender por meio do desafio das próprias convicções.

Os professores que estavam acompanhando estudantes apresentaram seus resultados com ou sem o uso de slides, tendo a possibilidade de uma conversa entre os participantes. Em seguida, cada membro do projeto responsável pela live apresentou a estrutura da atividade, como poderia ser aplicada em sala de aula e quais conteúdos extras poderiam abordar, destacando o processo de adaptação e planejamento da atividade, as metodologias utilizadas, objetivos, tempo de aplicação, materiais utilizados, resultados da aplicação das atividades de modo presencial, entre outros aspectos.

Alguns professores comentaram sobre a recepção dos estudantes, a falta de interesse da gestão da escola, o empenho de ir até a escola pegar material e distribuir para os estudantes que estavam em casa, alguns desentendimentos com professores de outras disciplinas sobre o excesso de carga na disciplina de matemática, além de expor que utilizaram as atividades para elaborar outras sequências didáticas ou materiais para explicarem os conteúdos abordados nas lives ou novos conteúdos. Foi possível notar que os professores costumavam enfrentar as mesmas dificuldades na pandemia, como a qualidade de internet e a disponibilidade dos estudantes, os professores relataram frases do tipo "os alunos estão sobrecarregados de atividades relacionadas às escolas".

Além das discussões sobre as atividades, os professores compartilharam experiências escolares, de cursos de formação, de projetos. O espaço era aberto para novas ideias e sugestões, tanto sobre as atividades como a forma de acontecer as webconferências. Sempre era questionado sobre o que estavam achando, se gostariam de alguma mudança, e muito do que os professores relatavam ajudavam a equipe do projeto na preparação das atividades, pois passávamos a conhecer um pouco mais sobre as realidades dos professores e estudantes. 
É importante destacar que o papel do professor inscrito no projeto foi tanto de formando quanto de formador, isso porque nesse espaço houve um compartilhamento de experiências e de saberes, indo de acordo com Nóvoa (1992, p. 14) ao dizer "A troca de experiências e a partilha de saberes consolidam espaços de formação mútua, nos quais cada professor é chamado a desempenhar, simultaneamente, o papel de formador e de formando."

Como estamos expondo sobre as webconferências, apresentaremos algumas respostas dos questionários sobre a participação dos professores. Destacamos três questões: a importância na participação dos encontros on-line; pontos positivos e negativos nesse compartilhamento de experiências; e as dificuldades em participar das webconferências.

Os professores relataram que as webconferências foram importantes pela exposição de diferentes visões sobre as atividades e dificuldades dos estudantes, comentaram sobre as experiências compartilhadas e as discussões realizadas, refletindo e adquirindo uma visão mais ampla do ensino de matemática. Segundo eles, os encontros ajudaram a visualizar outras ideias que passam despercebidas, como a etnomatemática e atividades criativas.

Nessa mesma linha de respostas, aparecem os pontos positivos em compartilhar as experiências com professores de vários estados, como:

Professor: Grande oportunidade de conhecermos a realidade da educação pelo Brasil. Momento de compartilharmos experiências, angústias e soluções.

Professor: Conhecer a realidade de outros lugares, as dificuldades que cada um enfrenta e perceber que mesmo longe há inúmeras semelhanças, boas e ruins, só tem como enriquecer a nossa formação.

Professor: Mostrar em prática as atividades feitas nas lives, as dificuldades que são encontradas e os pontos negativos.

Professor: Conhecer as culturas de outros estados e as realidades de cada escola.

(Depoimentos de professores participantes do projeto, 2020).

Os pontos negativos elencados foram a falta de se ter uma maior interação entre os professores, sugerindo ter um grupo de WhatsApp, e não ter um maior aprofundamento nos conteúdos matemáticos. Sobre esse segundo ponto, vale ressaltar que os professores eram instigados a sempre abordarem os conteúdos com maior profundidade, cada um levando em consideração a sua realidade.

O outro questionamento foi sobre as dificuldades que tiveram em participar das webconferências. A maioria dos professores que disseram ter dificuldade elencou sobre o horário que às vezes coincidia com reuniões da escola em que trabalham e outros relataram também sobre acesso à internet.

\section{Questionários aplicados aos professores}

Como já mencionamos na Seção 3, a equipe do projeto elaborou, por meio do Google Forms, o "questionário geral" e o "questionário específico" para verificar se os objetivos do projeto "Sem mais nem menos on-line" para os professores foram alcançados.

\subsection{Questionário geral}

Esse questionário foi destinado a todos os professores participantes, no qual quinze responderam. Alguns itens desse questionário já foram descritos anteriormente. Agora 
vamos nos deter aos outros questionamentos, visando verificar as possíveis mudanças dos professores após a participação no projeto.

Um dos questionamentos foi: "Você aponta alguma mudança na sua forma de pensar o Ensino de Matemática depois da participação no projeto de extensão 'Sem mais nem menos on-line'? Qual(is)?". Todos professores relataram que sim e alguns pontos elencados foram: poder trabalhar a matemática de modo descontraído com brincadeiras, danças e jogos; estar mais atento para observar questões matemáticas presentes ao nosso redor e ver as possibilidades de trabalhar com elas em sala de aula; trabalhar com construção como das malhas e com temas do dia a dia, como a dança e o folclore; olhar para situações do cotidiano e tentar ver a matemática nelas, usando isso para motivar os estudantes; usar materiais alternativos; aplicar melhor as metodologias ativas; proporcionar novas formas de ensinar matemática; trabalhar de forma dinâmica nas atividades.

Também foi questionado quais foram os benefícios que o projeto proporcionou. Dentre os relatos, vamos destacar alguns a seguir.

Professor: Conhecimento de vários aspectos culturais que eu não tinha idéia que poderia ser aplicado dentro das aulas de matemáticas.

Professor: Ter uma visão mais aguçada da etnomatemática; Criatividade para elaboração das aulas/atividades.

Professor: Um novo olhar da matemática no dia a dia. $O$ uso de materiais simples, o vínculo entre o que se trabalha na disciplina e a realidade, faz muita diferença com os estudantes.

Professor: Me considero agora uma pessoa ainda mais motivada a trazer o novo pra sala de aula e usar a criatividade para não permitir que a falta de recursos atrapalhe no desenvolvimento dos trabalhos potenciais.

Professor: Excelentes aprendizagens, acredito que posso me espelhar na metodologia de vocês e colocar em sala de aula.

Professor: Um leque de ideias e práticas pedagógicas.

Professor: Uma visão mais ampla sobre o ensino e aprendizagem dos conteúdos de matemática.

(Depoimentos de professores participantes do projeto, 2020).

Sobre as temáticas abordadas nas lives, foi questionado aos professores se já trabalharam algum dos temas apresentados. De acordo com as respostas, dos quinze professores, oito $(53,33 \%)$ não trabalharam e sete $(46,67 \%)$ trabalharam. Depois eles responderam se já tinham feito alguma abordagem de ensino seguindo a proposta das lives. Para esse questionamento, dez $(66,67 \%)$ relataram "Sim" e cinco $(33,33 \%)$ disseram "Não".

Como a ideia na abordagem das lives era apresentar a matemática relacionada ao dia a dia, eles responderam sobre a frequência que costumavam trabalhar a matemática presente no cotidiano. A maioria respondeu que trabalha frequentemente, mas destacaram que somente quando conseguem fazer essa relação, que não fazem de forma lúdica e/ou que depende do conteúdo. Um professor que respondeu "Pouca frequência", destacou "A partir de agora será muita frequência". Somente um professor disse que não trabalha.

Para finalizar, destacamos alguns comentários finais que os professores colocaram nesse questionário, de forma opcional.

Professor: Parabenizo a toda equipe do projeto. Sabemos que ainda há um processo de encurtar o espaço entre universidade e educação básica, mas essa iniciativa mostrou que podemos andar juntos. A forma de pensar os materiais alternativos nos mostra o quanto as atividades foram pensadas visando a equidade e a participação de todos. As IES públicas 
produzem muitas metodologias e atividades voltadas ao ensino, mas nem todas são replicáveis na educação básica pública e vocês conseguiram esse feito de produzir atividades que possam ser usadas em qualquer condição.

Professor: Gostaria de agradecer novamente a oportunidade, esse projeto é incrivel. Não é um projeto de ensino de Matemática apenas, é um projeto que ensina a enxergar. A ver potencialidades nos mais diferentes cantos. Ver que não faz sentido manter disciplinas isoladas, todas estão conectadas, assim como no mundo fora da escola. Um ensino assim é o que deveria prevalecer para formar sujeitos de fato críticos. Parabéns equipe!

Professor: Gostaria de parabenizar o projeto por trazer novas ferramentas que possam agregar para o ensino da matemática e fazer com que os alunos interajam mais com essa disciplina fantástica.

(Depoimentos de professores participantes do projeto, 2020).

Essas primeiras respostas já confirmam o quanto o projeto fez diferença na mudança de postura desses professores, com destaque para o pensar em novas metodologias de ensino, relacionar a matemática com o cotidiano e a motivação.

\subsection{Questionário específico}

Agora veremos as respostas do "questionário específico" enviado aos professores do grupo "Acompanhante de alunos e participante das webconferências". Decidimos realizar esse questionário porque esse grupo teve papel diferenciado no projeto. Como mencionado anteriormente, esse grupo de professores, além de participar das webconferências, também ficaram responsáveis por estudantes durante o projeto.

Os dez professores que responderam representam nove escolas públicas (estadual, municipal e federal) e duas escolas particulares, isso porque um dos professores leciona em duas das escolas. Além disso, eles lecionam em turmas do 60 ano do Ensino Fundamental até a 2a série do Ensino Médio.

Algumas questões foram voltadas para sabermos como foi feito o acompanhamento dos estudantes por parte dos professores.

O meio mais utilizado para acompanhar os estudantes foi o WhatsApp, sendo indicado por oito professores, mas também indicaram outros meios. Alguns professores usaram diversas possibilidades digitais para acompanhar seus estudantes, ver no Gráfico 3.

Gráfico 3-Quantidade de professores que utilizaram alguns recursos digitais durante o projeto.

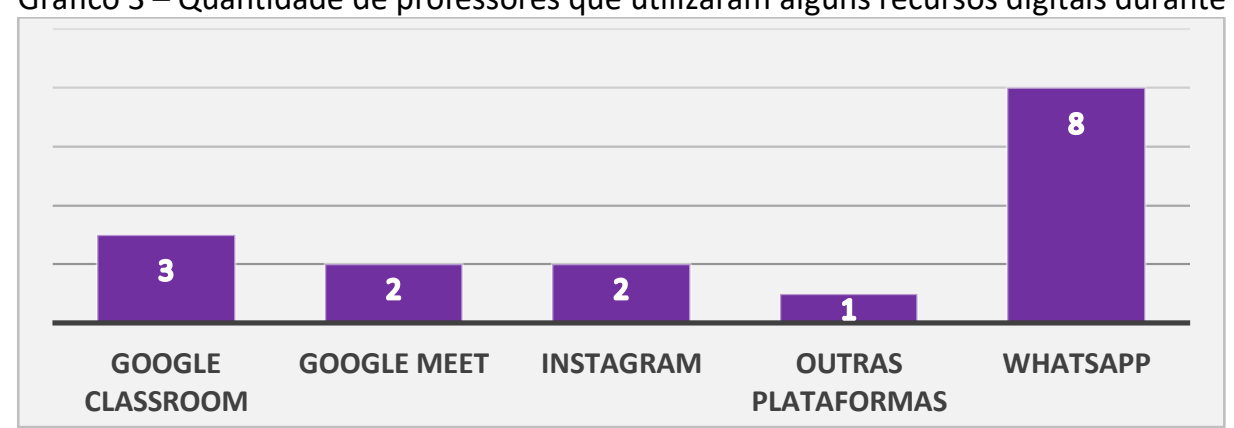

Fonte: Arquivo do projeto de extensão "Sem mais nem menos on-line", 2020.

Sobre como foi feito o acompanhamento, recebemos as seguintes respostas: seis professores (60,00\%) afirmaram lembrar os estudantes com frequência de assistirem as lives, incentivavam a participação deles e, se preciso, faziam resumos ou vídeos para auxiliá- 
los nas resoluções das atividades, por meio de grupo criado no WhatsApp; dois professores $(20,00 \%)$ afirmaram fazer chamadas on-line para discussão com os estudantes sobre as lives; um professor $(10,00 \%)$ afirmou que sempre falava com eles usando o chat do Google, lembrando das lives, enviando resumos das atividades propostas e respondendo dúvidas; e um professor $(10,00 \%)$ afirmou que auxiliou respondendo sobre os materiais que eram enviados.

Os professores também relataram sobre as estratégias utilizadas para instigar os estudantes a participarem das lives e a forma que acharam para conciliar as atividades da escola com as do projeto. A maioria dos professores, cinco deles $(50,00 \%)$, respondeu que utilizaram estratégias diversas. Mas também tivemos mais dois tipos de respostas: três $(30,00 \%)$ beneficiaram os estudantes com pontos extras e dois $(20,00 \%)$ apenas divulgaram via WhatsApp. Vejamos algumas respostas:

Professor: Criação do grupo de whatssap para uns incentivarem os outros e para avisos de horário e materiais das lives, criação de um ranking para vermos quem participava das lives e devolvia as atividades, tivemos sorteios de caixas de chocolates e teremos uma rodada de pizza com os participantes (financiada pelos professores e direção) assim que possivel, devido ao isolamento.

Professor: Incentivando por meio de apoio, auxiliando nas atividades, aqueles que não podia acompanhar as lives, baixei os vídeos e enviava o link no grupo.

Professor: Vídeo chamadas, mensagens em grupos de Watzap com divulgação da mídia enviada pelo sem mais nem menos.

(Depoimentos de professores participantes do projeto, 2020).

Sobre a forma como conciliaram as atividades das lives com as atividades obrigatórias da escola, tivemos diferentes tipos de respostas dos professores: dois (20,00\%) afirmaram que substituíram as atividades escolares pelas atividades do projeto (apesar de esse não ser o intuito do projeto); dois $(20,00 \%)$ se apropriaram dos temas para trabalhar conteúdos que se adaptavam com as atividades das lives; dois $(20,00 \%)$ afirmaram que as atividades das lives não coincidiam com as atividades da escola, porém encontraram algumas dificuldades nos materiais deixados pós lives, pois acumulavam com as atividades passadas por outros professores; dois $(20,00 \%)$ afirmaram ter dificuldade em conciliar as lives com as atividades obrigatórias; um (10,00\%) respondeu "madrugando muito"; e um professor $(10,00 \%)$ disse que pediu permissão a outro professor para ceder um dia extra e trabalhar as atividades do projeto. Seguem alguns comentários:

Professor: Sempre que havia uma live eu me apropriava do tema para dar sequência nas minhas próprias atividades, mandando materiais de temas relacionados. Inclusive foi bem simples, pois a maioria dos temas era adaptável ao currículo do sétimo ano.

Professor: Eles estavam esgotados com o conteúdo escolar e a maioria nem estava participando por não conseguir acessar a plataforma. Foi combinado então que iríamos fazer só a atividade do projeto e que o aluno que não se sentisse confortável poderia fazer as atividades regulares anteriores.

Professor: Felizmente no dia escolhido para a live não tinha aula on-line para os estudantes, $o$ difícil foi conciliar as atividades de casa (deixadas pelos outros professores) com as atividades da live. A estratégia era após a live discutíamos no grupo e já deixávamos as questões bem encaminhadas para o dia seguinte. Nas últimas lives tivemos problemas, pois muitos estudantes não estavam interagindo nem nas aulas remotas, nem nas lives e foi pensada uma gincana remota para motivá-los a voltar a participar das aulas. Atrapalhou um pouco, 
pois a gincana foi a semana inteira, mas consegui incluir uma atividade de geometria inspirado nas atividades das lives (foi bem legal).

(Depoimentos de professores participantes do projeto, 2020).

Foram questionados também se exploraram conteúdos diferentes com as atividades apresentadas nas lives e se elaboraram algum material extra para ajudar os estudantes na realização das atividades.

Nove deles (90,00\%) afirmaram aproveitar as atividades das lives para abordar ou revisar algum conteúdo. Seguem alguns dos comentários sobre isso:

Professor: Sim. alguns conceitos que eles não conheciam, como plano cartesiano, polígonos, entre outros.

Professor: Aproveitei para aprofundar cada conteúdo. Geralmente não trabalho com geometria, pois é a última parte do currículo, então pude apresentar a eles de uma forma super lúdica."

Professor: Eu tive a oportunidade de explorar com meus alunos do Ensino Médio um conteúdo que só vi na faculdade, o qual no terceiro ano, na parte de geometria espacial números triangulares.

Professor: Em decorrência da live o guerreiro Alagoano entrei nos conceitos de álgebra, expressões algébricas, incógnitas, variáveis, equações. A live foi uma ótima introdução!

(Depoimentos de professores participantes do projeto, 2020).

Cinco professores (50,00\%) afirmaram ter preparado algum material extra para trabalhar com os estudantes e cinco professores $(50,00 \%)$ responderam que não. Os materiais extras elaborados por eles foram: vídeos, roteiros, resumos e exercícios. Segundo os professores, vídeos menores eram feitos para possibilitar que os estudantes com problemas de internet conseguissem fazer as atividades, vídeos com um passo a passo mais devagar de construções para ajudar os estudantes em compreender melhor e sobre conteúdos matemáticos que eles ainda não tinham estudado, resumos dos conteúdos exibidos nas lives e exercícios relacionados aos temas abordados.

Para finalizar, alguns professores também colocaram comentários extras e opcionais no formulário. Vejamos alguns:

Professor: Grato pela oportunidade [...] com este projeto, que sem sombra de dúvidas vai acrescentar a minha prática docente aulas dinâmicas $e$ inovadoras estimulando $o$ aprendizado em matemática e será um diferencial na vida dos nossos estudantes.

Professor: Quero agradecer pela oportunidade de participar do projeto, tive excelentes momentos de aprendizagem e troca de experiência com os colegas (tanto os ministrantes quanto os colegas participantes). Projetos como esse me estimula a buscar ser cada vez melhor para o aluno, é como se desse uma injeção de ânimo para que eu continue dando o melhor de mim apesar das adversidades. Obrigada.

Professor: Parabenizo a equipe por esse projeto que pode ser acessivel e muito produtivo para o momento que estamos vivenciando.

(Depoimentos de professores participantes do projeto, 2020).

De acordo com os comentários, os professores consideraram que o projeto ajudou na prática docente e contribuiu para motivá-los a buscar meios para melhorar essa prática. 


\section{Considerações finais}

Neste artigo descrevemos ações do projeto de extensão "Sem mais nem menos online", mais especificamente nos atentamos para a participação dos professores de matemática da Educação Básica. As primeiras ações do projeto aconteceram no período de maio a agosto de 2020 e um dos objetivos dele foi oportunizar a participação de professores da escola pública ou privada, contribuindo com a formação continuada de professores.

Com a pandemia da Covid-19, muitos professores passaram a desenvolver atividades de forma virtual e o desafio de diminuir a falta de interesse dos estudantes na disciplina de matemática aumentou. $O$ projeto veio para compartilhar saberes entre docentes e discentes da universidade, e professores da Educação Básica, buscando uma melhoria no ensino de matemática e valorizando uma formação continuada de forma colaborativa e on-line.

Apesar de muito se discutir sobre formação continuada de professores, nem sempre tais cursos levam em consideração os saberes docentes, são carentes de propostas de novas metodologias de ensino e por diversas vezes acontecem distante da escola. Se pensarmos em formações on-line, isso torna-se ainda mais evidente. Buscamos no projeto aproximar a teoria, a prática e a realidade do professor, sempre considerando os saberes experienciais dos professores. Os professores participantes colaboraram para atingir os objetivos do projeto, além de compartilhar e repensar seus saberes, sendo também sujeitos do conhecimento.

O projeto aconteceu por meio de lives no Instagram para os estudantes e webconferências com os professores, proporcionando momentos descontraídos e interessantes de aprender matemática, mostrando também diversas alternativas atrativas de abordar conteúdos matemáticos atrelados ao cotidiano dos estudantes.

Em relação às lives, os professores aproveitaram essa oportunidade para relembrar, conversar e discutir sobre diversos conteúdos matemáticos, inclusive fazendo atividades extras e complementares. Eles também destacaram sobre a forma de abordar a matemática com o cotidiano, o uso de materiais alternativos e o fato de os próprios estudantes elaborarem seus materiais, dizendo inclusive que iriam passar a usar também nas atividades presenciais. Em relação às webconferências, destacaram ser importante esse espaço em que puderam conhecer diversas realidades, compartilhar experiências, angústias e possíveis soluções.

Os professores afirmaram ter tido alguma mudança na forma de pensar o ensino de matemática depois da participação do projeto, ressaltando a possibilidade de trabalhar a matemática de modo descontraído, observar a matemática no dia a dia, usar materiais alternativos, aplicar melhor as metodologias ativas, entre outras. Dessa forma, os objetivos do projeto de extensão "Sem mais nem menos on-line" foram atingidos, mostrando assim que o projeto pode contribuir com a formação continuada de professores de matemática.

\section{Referências}

BOAVIDA, Ana Maria; PONTE, João Pedro da. Investigação colaborativa: Potencialidades e problemas. In GTI (Org). Reflectir e investigar sobre a prática profissional. Lisboa: APM, 2002. Disponível em: https://repositorio.ul.pt/bitstream/10451/4069/1/02-Boavida-Ponte\%20(GTI).pdf. Acesso em: 24 nov. 2020. 
CHARLOT, Bernard. A Noção de relação com o saber: bases de apoio teórico e fundamentos antropológicos. In: CHARLOT, Bernard (Org.) Os jovens e o saber: perspectivas mundiais. Tradução de Fátima Murad. Porto Alegre: ARTMED Editora, 2000.

FERREIRA, Ana Cristina. O trabalho colaborativo como ferramenta e o contexto para o desenvolvimento profissional: compartilhando experiências. In: NACARATO, Adair Mendes; PAIVA, Maria Auxiliadora Vilela. A formação do professor que ensina matemática: perspectivas e pesquisas. 3. ed. Belo Horizonte: Autêntica, 2013.

MANRIQUE, Ana Lúcia; ANDRÉ, Marli E. D. A. Relações com saberes na formação de professores. In: NACARATO, Adair Mendes; PAIVA, Maria Auxiliadora Vilela. A formação do professor que ensina matemática: perspectivas e pesquisas. 3. ed. Belo Horizonte: Autêntica, 2013.

NÓVOA, António. Formação de professores e profissão docente. In: NÓVOA, António (coord.). Os professores e a sua formação. Lisboa: Dom Quixote, 1992. Universidade de Lisboa. Disponível em: https://repositorio.ul.pt/bitstream/10451/4758/1/FPPD_A_Novoa.pdf. Acesso em: 22 nov. 2020.

SANDES, Joana Pereira; MOREIRA, Geraldo Eustáquio. Educação matemática e a formação de professores para uma prática docente significativa. Revista @mbienteeducação. São Paulo: Universidade Cidade de São Paulo, v. 11, n. 1, jan./abr. 2018. Disponível em: http://publicacoes.unicid.edu.br/index.php/ambienteeducacao/article/view/49/471. Acesso em: 24 nov. 2020.

SANTOS, Viviane de Oliveira; ALBUQUERQUE, Erenilda Severina da Conceição; SANTOS, Késsia Tatiane Rodrigues dos; OLIVEIRA, Wanessa Cavalcanti. Lives no Instagram envolvendo matemática no dia a dia: contribuições do projeto "Sem mais nem menos on-line" para estudantes e professores da Educação Básica. PMO, v.9, n.1, 2021. Disponível em: http://pmo.sbm.org.br/wpcontent/uploads/sites/16/dlm_uploads/2021/02/art4_PMO_Chamada_Tematica_2020_SBM.pdf. Acesso em: 06 set. 2021.

SANTOS, Viviane de Oliveira; CORREIA, Nickson Deyvis da Silva; NASCIMENTO, Daniela Aprigio do. Matemática nas estações do ano: o uso de materiais didáticos no ensino de matemática. Revista Paranaense de Educação Matemática, 10(21), 463-486, 2021. Disponível em: http://revista.unespar.edu.br/index.php/rpem/article/view/941. Acesso em: 06 set. 2021.

Sem mais nem menos. Disponível em: https://sem-mais-nem-menos.webnode.com/. Acesso em: 24 nov. 2020.

TARDIF, Maurice. Saberes Docentes e Formação Profissional. 13. ed. Petrópolis, RJ: Vozes, 2012. 